\title{
Correction: Efficacy of H-shaped incision with bovine pericardial graft in Peyronie's disease: a 1-year follow-up using penile Doppler ultrasonography
}

Jin Bong Choi · Dong Sup Lee

Published online: 7 August 2020

(c) The Author(s), under exclusive licence to Springer Nature Limited 2020

Correction to: International Journal of Impotence Research https://doi.org/10.1038/s41443-020-0312-y

The original version of this Article was updated shortly after publication when a serious error was discovered in the abstract. The third sentence should read "The degree of penile curvature in all subjects was $>60^{\circ}$ ", not "The degree of penile curvature in all subjects was $<60$ ".

This error has now been corrected in the PDF and HTML versions. 